\title{
A new plant growth system rig based on thermodynamic solar energy: a study for energy efficiency assessment
}

\author{
João Paulo Coelho ${ }^{1,2}$, José Gonçalves ${ }^{1,2}$, Manuel Braz César ${ }^{1,3}$, and José Dias ${ }^{1}$ \\ 1 Instituto Politécnico de Bragança, Escola Superior de Tecnologia e Gestão, Campus \\ de Sta. Apolónia, 5300-253 Bragança, Portugal \\ 2 INESC TEC Technology and Science, Campus da FEUP, 4200 - 465 Porto, Portugal \\ 3 CONSTRUCT R\&D Center, Faculty of Engineering of the University of Porto, \\ Porto, Portugal \\ \{jpcoelho, goncalves, brazcesar\}@ipb.pt
}

\begin{abstract}
At the present there is a high pressure toward the improvement of all production processes. Those improvements can target distinct factors along the production chain. In particular, and due to recent tight energy efficiency policies, those that involve energy efficiency. As can be expected, agricultural processes are not immune to this tendency. Even more when dealing with indoor productions. In this context, this work presents an innovative system that aims to improve the energy efficiency of a trees growing platform. This improvement in energy consumption is accomplished by replacing an electric heating system by one based on thermodynamic panels. The assessment of the heating fluid caudal and its temperature was experimentally obtained by means of a custom made scaled prototype whose actuators status are commanded by a Fuzzy-based controller. The obtained results suggest that the change in the heating paradigm will lead to overall savings that can easily reach $60 \%$ on the energy bill.
\end{abstract}

Keywords: Energy efficiency, Renewable energy, Fuzzy Controller, Agriculture.

\section{Introduction}

Nowadays, in order to increase the companies competitiveness, all the production processes are subject to rigorous audits. The output of such studies leads to changes in several key variables that will, ultimately, give rise to a performance increase. Those changes can happen at multiple levels, ranging from plant layout, tasks scheduling, rework or scrap minimization and, of course, energy efficiency.

Energy efficiency is a pressing problem that is addressed at several levels. Particularly in the countries that are part of European Union (EU), there are currently several political mechanisms undergoing pushing for energy consumption reduction and, simultaneously, to promote renewable-based energy production systems [1]. 
Since economic growth is tightly connected to an increase in energy consumption, the way to cope to the EU energy policies while simultaneously maintaining the upward trend on the economic behaviour, will be to replace the current processes feeding energy solutions by more efficient ones. In particular energy production methods that will not scale up with the required economic development as the ones existing nowadays.

Even if unnotice, agricultural processes are not immune to this tendency. As a matter of fact, agricultural production systems require lot of energy and natural resources such as water. Within a global market paradigm, the costs reduction, while maintaining the products quality, is a constant grower concern. Hence keeping market competitiveness can then be a challenge tackled at both operational and technological fronts.

Regarding the latter, it is often possible to transpose solutions used in different contexts to alternative applications bringing increased value to a new process. For example the water heating systems, based on thermodynamic pumps used in domestic applications, can be also used in agricultural processes as is the case of greenhouses productions.

This paper deals with a new devised strategy to improve the energy efficiency of a tree nursing station. It is intended to replace the current resistor based heating system by an alternative solution using circulation of hot water in a closed pipe circuit. The heating and recirculation of the water will be performed by a thermodynamic solar system composed by a heat pump and solar thermal collectors.

However, prior to the effective implementation of this solution, it is required to test if this alternative heating system can, in fact, be used to replace the old one. In order to do this a scaled version of a growing platform was built where the thermodynamic heating system was replaced by a butane gas water heater system. Both the water pump and the gas heating system must be controlled taking into consideration the imposed temperature set-point while maintaining system integrity. The actuator states will be function of exogenous information, provided by an array of sensors, and a control law imposed by a Fuzzy controller. The choice of this control strategy was mainly due to the fact that, under this paradigm, an expert based controller is easily translated to a Fuzzy behaviour system [6] leading to a reduced controller development time.

The remain of this paper will be divided into four additional sections. After a more thorough presentation of the addressed problem at Section 2, the Fuzzy controller design strategy will be described along Section 3. Here the obtained results, regarding both set-point tracking and actuator wearing, will be presented. The economic viability of the purposed method will be described during Section 4. Final concluding remarks, as well as future work directions, will be presented in Section 5. 


\section{Problem Description}

One of the main objectives of this work is to evaluate the economic profit that could be obtained from replacing the current heating system of a plant growth system by a renewable energy-based system.

This trees growing system consists on platforms placed inside greenhouses where the air temperature is roughly controlled. In particular, the inside air temperature ranges, in average, from 10 to $30^{\circ} \mathrm{C}$. The current growing platforms installation spans five distinct agricultural buildings as can be seen from Figure 1a. All the platforms have the standard width of 1,6 meters. The greenhouse identified by the letter $\mathbf{A}$ has 3 growing platforms each one with 10 meters long and the one denoted by $\mathbf{B}$ has two platforms also with 10 meters long. The building distinguished by $\mathbf{C}$ does not have any growing platform installed. Building $\mathbf{D}$ has two of them, each one with five meters long, and building $\mathbf{E}$ has only one five meters long platform.

At the present the installed growing platforms are used to nurse olive trees and chestnuts, among others, until they are sufficiently resistant to be planted outdoors [3]. The system structure is composed by a metallic tray, covered with perlite, and with an electric resistance coil running along the covered area. The power consumption of this heating system goes around $1 \mathrm{~kW}$ per meter of platform length. Figure 1b depicts one of the above referred platform system.

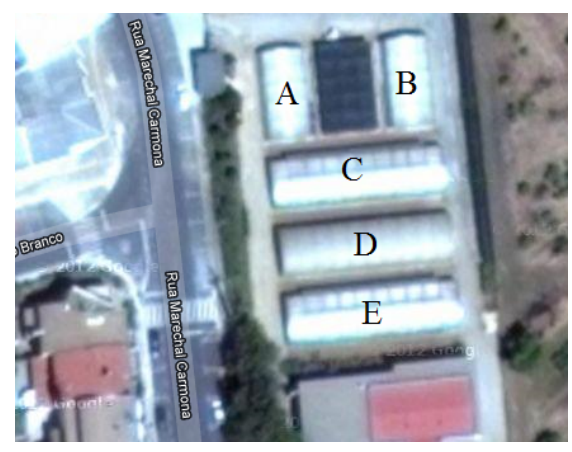

(a) Aerial view of the production greenhouses $\left(41^{\circ} 47^{\prime} \mathrm{N}, 6^{\circ} 45^{\prime} \mathrm{W}\right)$.

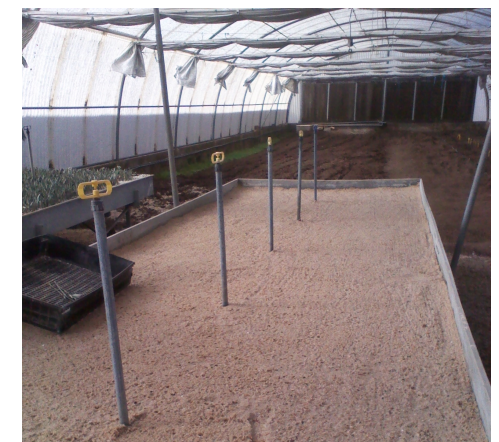

(b) Growing platform inside the greenhouse. The center pipes are for irrigation purposes.

Fig. 1: Greenhouses based platform growing system.

The current installation is equivalent to 65 meters of production platform which is equivalent to an installed capacity of around $65 \mathrm{~kW}$. During the winter time, when the indoor temperatures are lower, the average energy spent in the growing platforms is around $100 \mathrm{kWh}$ per day. Assuming an average cost of 0.25 euros per $\mathrm{kWh}$ this will lead to a total of 25 euros per day. This number is excessive and import high production costs. In order to reduce it, an alternative 
heating system was devised by replacing the inefficient resistance based heating element by a water heating system driven by a solar thermodynamic panels system $[9,5]$. The devised heating process is straightforward as can be exemplified in the diagram of Figure 2.

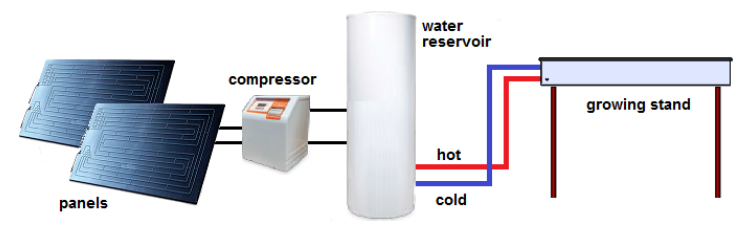

Fig. 2: Block diagram of the growing platform heating system.

Since both the water temperature and flow requirements for the new devised heatig system, under nominal and extreme conditions, are unknown, a scaled prototype was built. First of all the test rig was implemented using galvanized steel: the same material used in the already existent greenhouse stands. Only its dimensions was scaled down to a platform of $1,25 \mathrm{~m} \times 0,65 \mathrm{~m}$. The height of $18 \mathrm{~cm}$ was deliberately let equal to the original in order to easily integrate the solution devised for the prototype into the real system.

The heated water piping system was embedded in a special modelled styrofoam as shown in Figure 3a. Then this assembly was placed inside the metal frame and filled with around $5 \mathrm{~cm}$ of dry sand and $10 \mathrm{~cm}$ of perlite.

In the developed test rig, the thermodynamic heating system was replaced by a butane gas heating. This operating change was mainly due to controllability and logistics. Nevertheless, the information that one seeks to find could also be easily obtained by this new approach. Figure 3b shows an image of this alternative structure.

Additionally an array of sensors was scattered along the system in several key points. Six waterproof temperature sensors (DS18B20) were distributed along the perlite surface. This set of sensors allows to analyse how well and uniform the heat spreads along the working area. In addition other temperature sensors are available: one to measure the heater outlet water temperature, the water temperature at a reservoir and the environment air temperature. The water flow is also measured through a flow sensor.

The water is made circulating by means of a $1 / 2 \mathrm{HP}$ water pump system as can be observed in Figure 3c. The water pump is connected to the gas heater system by means of 1 inch pipes. On the other hand, the heater outlet pipe feeds the growing table. The circuit is closed by means of a return pipe from the table to the reservoir.

The control and data acquisition system was built around an Arduino Uno R3.0 [2]. Most temperature sensors connect to the micro-controller board by means of One-Wire communication protocol. Others require the use of an ana$\log$ to digital (A/D) input. The time is kept tracked using a real-time clock 
(RTC) and data is locally saved in a secure digital (SD) memory card. The former is connected to the Arduino Uno platform using an inter-integrated circuit communication protocol $\left(\mathrm{I}^{2} \mathrm{C}\right)$ and the latter by serial peripheral interface (SPI). This hardware setup can be observed in Figure 3d.

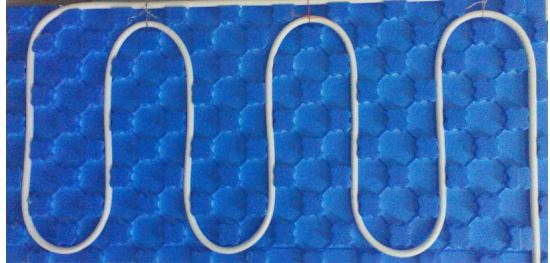

(a) The growing platform internal piping system.

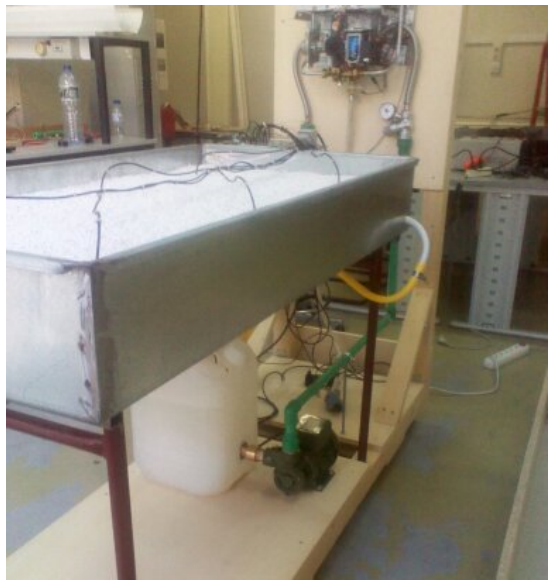

(c) Detail on the water system. Below the table it is possible to observe both the water pump and the reservoir.

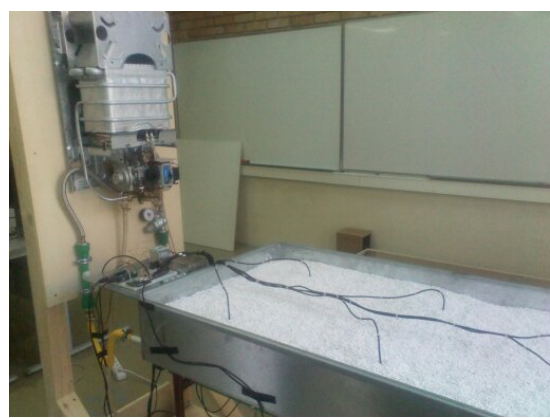

(b) Distribution of the temperature sensors along the perlite.

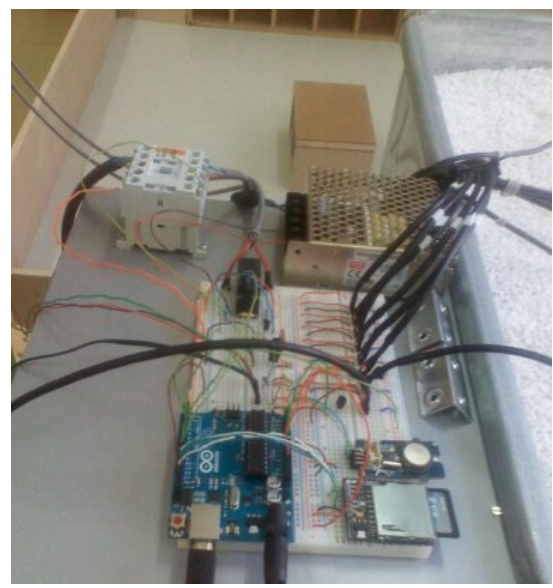

(d) Control and data acquisition hardware built around an Arduino Uno board.

Fig. 3: Experimental rig components.

The trees nursing process requires that the surface temperature be maintained around $23^{\circ} \mathrm{C}$. In this process the main external disturbances are the indoor air temperature fluctuations and the load imposed by periodic irrigations. However, in this work, the latter is not considered.

In order to cope with the required surface temperature set-point two manipulated variables are available. The heater and the water pump states. Both have 
an important role in temperature regulation that will be further explained in the next section along with the control law devised to regulate this system.

\section{The Fuzzy Controller}

Besides set-point tracking, the addressed system also requires water temperature supervision in order to prevent the system collapse. Moreover, due to the actuators nature, a bang-bang approach to control was performed. Moreover, and in order to easily design a MIMO controller by emulating its behaviour through an expert system paradigm, a Fuzzy-based controller was devised [2].

The controller design was carried out using the MatLaB ${ }^{\circledR}$ Fuzzy Logic Toolbox taking into consideration empirical knowledge. The controller structure, within the Fuzzy Toolbox context, can be observed in Figure 5a. This is a multi-input, multi-output controller system whose inputs are the average perlite surface temperature and the water temperature inside the reservoir. The output variables are the heater and water pump states.

The fuzzy inference mechanism selected was a Mamdani type [7,8]. Moreover the conjunction and disjunction operation rules were the minimum and maximum respectively. The defuzzification process is carried out by means of a centroid operation over the feature space.

Concerning the surface temperature variable, the input space was partitioned into five Gaussian type Fuzzy sets. Each one was labelled as 'cold', 'cool', 'good', 'warm' and 'hot'. This fragmentation can be depicted from Figure 4a.

Regarding the reservoir water temperature, the input space was divided into three sets labelled 'cold', 'good' and 'hot'. The sets distribution along the input space range can be observed in Figure $4 \mathrm{~b}$. On the other hand, the output space for the water pump was split into three triangle type membership functions as can be concluded from Figure 4c. The same operation was carried out for the heater variable. However, in this case, a five membership functions set was used to describe the output space. Nevertheless the same triangular shape membership functions were used as in the previous case as can be seen from Figure 4d.

The Fuzzy controller rules were produced automatically by the MATLAB ${ }^{\circledR}$ software. In particular a total of 15 rules were generated. This rule based controller structure can be easily analysed by means of a graphical output available from the toolbox. A screenshot of this rule viewer graphical tool is presented in Figure 5b.

In the next section the above designed Fuzzy controller behaviour will be presented. Its performance will be analysed regarding both set-point tracking and actuators stress. Even if the former figure of merit can be slightly relaxed the latter is of extreme importance in order to reduce wearing of both the water pump and the gas heating system by preventing high frequency switching states.

Several tests were performed, always giving priority to the worst case scenario, with ambient temperatures close to $10^{\circ} \mathrm{C}$. In all the performed tests the desired set-point temperature is considered constant and equal to $23^{\circ} \mathrm{C}$. Below 


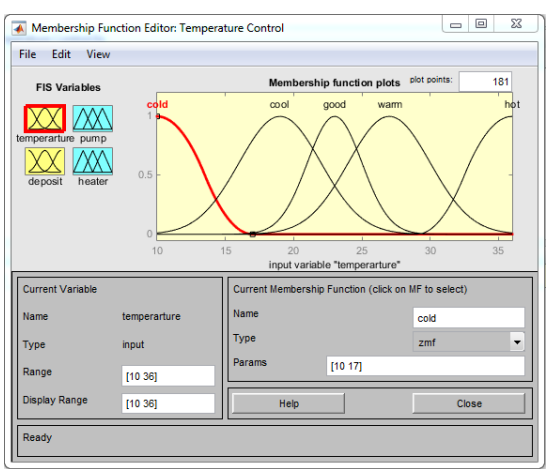

(a) Surface temperature fuzzification. This input variable was differentiated into five partially overlapped sets.

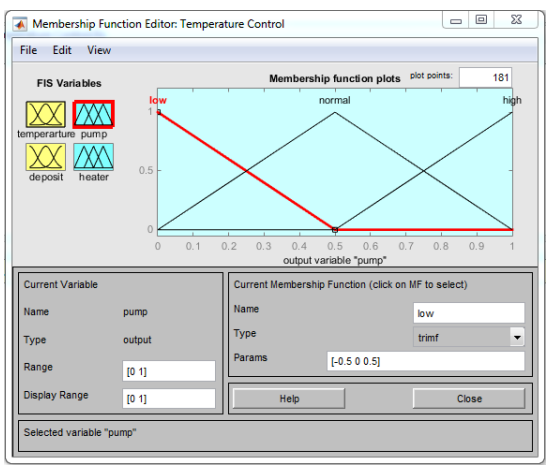

(c) Output space partition for the water pump using three triangle shaped membership function.

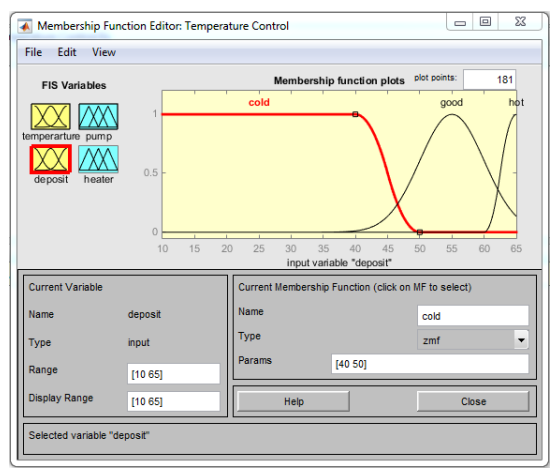

(b) Reservoir water temperature fuzzification. Three sets were used over the range from $10^{\circ} \mathrm{C}$ to $65^{\circ} \mathrm{C}$.

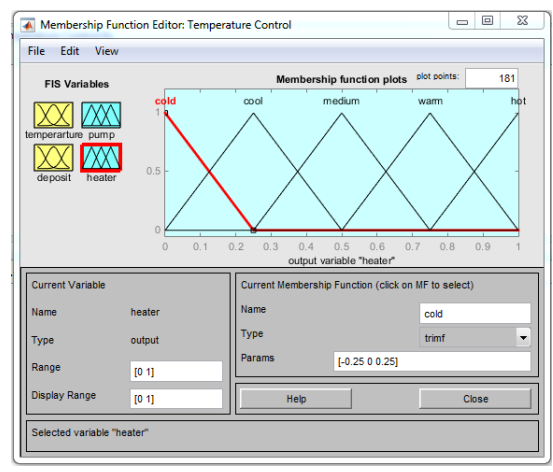

(d) Output space partition for the gas heating system using five triangular shaped membership functions.

Fig. 4: Input and output fuzzy partition space.

are presented the results of two tests. The first, whose results are illustrated in Figure $6 \mathrm{a}$, has a temperature starting point of around $16^{\circ} \mathrm{C}$.

A second experiment, with lower water temperature starting point, was also performed. In this second case the initial system temperature is approximately $14^{\circ} \mathrm{C}$ and the average temperature environment stays around $11^{\circ} \mathrm{C}$. The obtained results are presented in Figure $6 \mathrm{~b}$.

From both experiments it is possible to conclude that, in both cases, the controller was able to reach, and maintain, the set-point temperature. Moreover one can see that the closed loop system exhibits an over-damped response type. In addition it is possible to observe the heater state change during the operation. Notice that the water pump state did not change during the experiments and was always on. From the obtained data it is possible to conclude that the rate of change of the heater state has a period of around 30 minutes. Hence the designed 


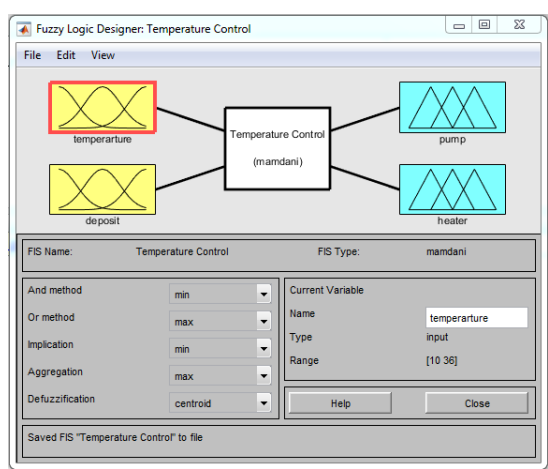

(a) Overall Fuzzy controller structure and parametrization.

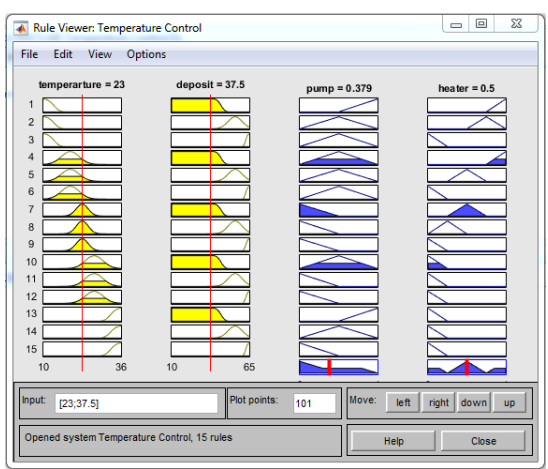

(b) The rule viewer assuming an surface temperature of $23{ }^{\circ} \mathrm{C}$ and a reservoir water temperature of $37.5^{\circ} \mathrm{C}$.

Fig. 5: Controller structure and internal operative rules.

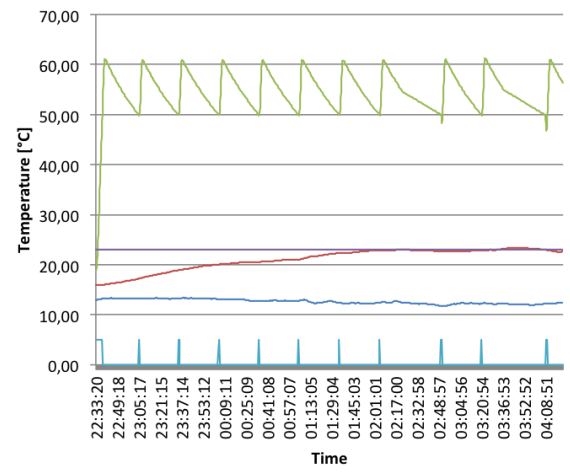

(a) Results obtained during the first test.

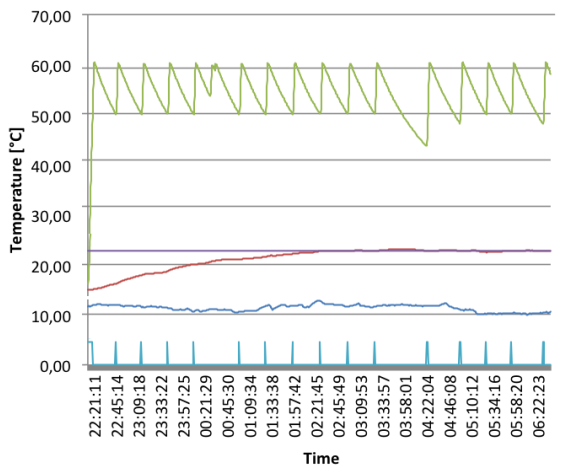

(b) Results obtained after test two.

Fig. 6: Measured results. From top to bottom one can observe the following curves: deposit water temperature, temperature set-point, average surface temperature, ambient temperature and heater control signal.

controller did not lead to an aggressive closed loop response from the actuators point-of-view.

\section{Cost analysis and economic viability}

From the performed test we have concluded that the circulating water temperature must be around $55^{\circ} \mathrm{C}$. The water mass needed, per meter of platform, is around 5 liters. For 65 meters long platform sets it will be needed to maintain, at least, 325 liters of water at the target temperature (for the worst case scenario). Those conditions can be easily kept by a typical thermodynamic solar 
system. For example the Eco450is commercialized by the ENERGIE ${ }^{\circledR}$ company is capable of heating 450 liters of water and only requires a peak power lower than $1 \mathrm{~kW}$ to produce around $3 \mathrm{~kW}$ of thermal power. This system combines a heat pump and two solar thermal collectors. The refrigerant fluid enters the solar panel and gains heat. After this stage the heat is transferred to a heat exchanger, through the help of a small compressor, which heats the water. Since the cooling fluid has a boiling temperature point of approximately $-30^{\circ} \mathrm{C}$, the system works even with the complete absence of sunlight [4].

The price of this system is around 4000 euros and will reduce, at least, the electrical energy consumption by a factor of 3 . This will lead to a mensal saving of around 250 euros. Hence the value of the equipment can be amortized in a time period less than one and a half years. Assuming an equipment average operating time of 20 years, more than 18 years of energy savings can be supposed. Neglecting the evolution of the money value along time, and that the system will only operates in half of the year, more than 20,000 euros can be saved along the assumed operating time.

\section{Conclusion}

This paper presents the economical viability of a new devised growing trees platform system based on thermodynamic panels. This alternative strategy, was proven to be economically viable, and may replace the older system whose heating system is based on electric elements. In order to infer about the applicability of this technique a scaled test rig was built. This test rig was used to evaluate if it was possible to attain the set-point temperature in the worst operating conditions and, if so, what would be the water temperature required and its mass flow. In the test rig the water was heated, not using the thermodynamic heating system, but a gas boiler whose state could be easily controlled and minimizing logistic problems. In addition, a half horse power water pump was installed, in order to make the water circulating. The pump operation was controlled by a simple on-off strategy. In order to maintain the system state variables in the required range a multi-input, multi-output Fuzzy controller was designed. The controller input is the temperature information collected by an array of sensors and its output signals are the commands for both the water pump and the gas heater. The choice of this controller paradigm was mainly due to its simplicity and proximity to empirical control based on expert knowledge. The designed controller was able to maintain the average surface temperature at the set-point level without generating any high frequency control signals. This is very important in order to reduce the wearing inherent to rapid on-off actuator state changes.

From the current results one can conclude that the replacement of the existent heating system by another based on thermodynamic solar system not only is viable but will also lead to an energy savings of more than $60 \%$.

However, further tests must still be performed using different operating conditions such as increased air temperature, adding moisture to the perlite substrate 
since, in real operating conditions, the irrigation system periodically sprinkle the small trees. It is necessary to analyse how this change in thermal conductivity will be noticed in the overall system performance.

\section{Acknowledgements}

This work is financed by the Project TEC4Growth - Pervasive Intelligence, Enhancers and Proofs of Concept with Industrial Impact / NORTE-01-0145FEDER-000020", which is financed by the North Portugal Regional Operational Programme (NORTE 2020), under the PORTUGAL 2020 Partnership Agreement, and through the European Regional Development Fund (ERDF).

\section{References}

1. Armstrong, F., Blundell, K.: Energy - beyond oil. Oxford University Press (2007)

2. Dhamakale, D., Patil, S.: Fuzzy logic approach with microcontroller for climate controlling in green house. International Journal on Emerging Technologies 2, 17$19(2011)$

3. Dumroese, R.K., Service, P.N.R.F., Luna, T., Landis, T.D. (eds.): Nursery manual for native plants. Nursery Management (Book 1), Forest Service (2009)

4. Energie: Energia solar termodinamica. Tech. rep., ENERGIE (2015)

5. Huiling, Z., Xiangzhao, F.: An experimental research on the application of ground source heat pump and floor-heating system in the greenhouse. Power and Energy Engineering Conference pp. 1-4 (2012)

6. Kia, P.J., Far, A.T., Omid, M., Alimardani, R., Naderloo, L.: Intelligent control based fuzzy logic for automation of greenhouse irrigation system and evaluation in relation to conventional systems. World Applied Sciences Journal 6(1), 16-23 (2009)

7. Mamdani, E., Assilian, S.: An experiment in linguistic synthesis with a fuzzy controller. nternational Journal of Man-Machine studies 7, 1-13 (1975)

8. Sakti, I.: Methodology of fuzzy logic with mamdani fuzzy models applied to the microcontroller. Information Technology, Computer and Electrical Engineering pp. 93-98 (2014)

9. Yang, Z., Pedersen, G., Larsen, L., Thybo, H.: Modeling and control of indoor climate using a heat pump based floor heating system. IECON 2007 - 33rd Annual Conference of the IEEE Industrial Electronics Society p. 29852990 (2007) 